DOI: 10.20472/IAC.2018.043.038

FILIZ RUHM

Plymouth State University, United States

\title{
ALT-RIGHT ACTIVISM, ALTERNATIVE FACTS AND PERSECUTION OF REFUGEES IN THE UNITED STATES
}

\begin{abstract}
:
Syrian displacement began in late 2011 and intensified between 2013 and 2016. With this intensification, the media coverage and political discourse in the United States shifted dramatically to demonize refugees, associating them with terrorism, and touting their potential as a grave security threat to the country. As a candidate, Donald Trump called "to stop the tremendous flow of Syrian refugees into the United States," citing their numbers -incorrectly- as reaching the "tens of thousands." Trump -repeatedly said that the U.S. government had little information about the Syrian refugees it accepted, asked for extreme vetting," drawing a link between refugees and a mass murder perpetrated by an American killer. Later, President-elect Trump accused Syrian refugees of links to terrorism, declaring that they are "definitely in many cases, ISIS-aligned." All these contributed to normalizing xenophobic and anti-refugee rhetoric. After January 20th, 2017 the Trump administration's March 6th Executive Order on immigration included a 120-day shutdown of the U.S. Refugee Resettlement program.

Though refugees are among the world's most powerless and marginalized groups, live in perilous legal and political limbo and mostly non-violent, this paper, based on social constructivist theoretical framework, will look into persecution of refugees by Alt-Right Activists in the U.S.
\end{abstract}

\section{Keywords:}

Refugee, activism, social constructivism 